University of Wisconsin Milwaukee

UWM Digital Commons

Geography Faculty Articles

Geography

2014

\title{
Forest Cover Changes in North Korea Since the 1980s
}

\author{
Sangjun Kang \\ Gyeonggi Research Institute \\ Woonsup Choi \\ University of Wisconsin - Milwaukee, choiw@uwm.edu
}

Follow this and additional works at: https://dc.uwm.edu/geog_facart

Part of the Geography Commons

\section{Recommended Citation}

Kang, Sangjun and Choi, Woonsup, "Forest Cover Changes in North Korea Since the 1980s" (2014). Geography Faculty Articles. 9. https://dc.uwm.edu/geog_facart/9

This Article is brought to you for free and open access by UWM Digital Commons. It has been accepted for inclusion in Geography Faculty Articles by an authorized administrator of UWM Digital Commons. For more information, please contact open-access@uwm.edu. 


\section{Title: Forest cover changes in North Korea 2 since the $1980 \mathrm{~s}$}

3 Running title: Forest cover changes in North Korea

\section{Authors}

5 Dr. Sangjun KANG

6 Department of Vision \& Strategy, Gyeonggi Research Institute

7 Suwon, Gyeonggi-do, REPUBLIC OF KOREA

8 Email: kangsangjun@gmail.com

10 Dr. Woonsup CHOI (corresponding author)

11 Department of Geography, University of Wisconsin-Milwaukee

12 P.O. Box 413, Milwaukee, Wisconsin, 53201-0413 USA

13 Phone: +1-414-229-2671 / Fax: +1-414-229-3981

14 Email: wchoi@alumni.illinois.edu

15

16 This article has been published in Regional Environmental Change and the final published

17 version is available at https://link.springer.com/article/10.1007/s10113-013-0497-4 


\section{Abstract}

21 North Korea used to have abundant forest stocks but underwent substantial deforestation and

22 degradation of forest in recent decades. This study examined morphological changes of forest

23 cover in North Korea between the 1980s and 2000s. Land cover data based on Landsat TM

24 imagery were obtained as images from the Republic of Korea's Ministry of Environment. The

25 images were processed and used for the Morphological Spatial Pattern Analysis and network

26 analysis. MSPA classified the forest cover into morphological classes such as core, islet, bridge,

27 perforation, edge, loop, and branch. The network analysis identified individual networks of forest,

28 each of which represents a patch of connected forest. The results are summarized as follows: (1)

29 Forest cover sharply decreased between the 1990s and 2000s, particularly in western provinces;

30 (2) Morphological classes indicating forest fragmentation such as islet, branch and edge

31 consistently increased in their fraction to the total area between the 1980s and 2000s; (3) Islet,

32 branch and edge also increased in number during the same period; (4) Forest networks shrank in

33 size and increased in number. Overall, the results demonstrate that deforestation and

34 fragmentation of forest occurred simultaneously in North Korea during the time.

35 Keywords: Morphological Spatial Pattern Analysis; network analysis; deforestation;

36 fragmentation; green infrastructure; North Korea 
40 North Korea (Democratic People's Republic of Korea) has very rugged terrain in most of the

41 country, particularly in the north and the east. Many streams originate from the mountains and

42 flow west- or eastward, producing some flat lands suitable for farming (Korea Institute for

43 National Unification 2009). In 1945, it was estimated that the area under forest was about 9.7

44 million hectares out of the land area of 12.3 million hectares (ca. 79\%), but it reduced to 8.2

45 million hectares in 1997 (Piddington 2003). A range of socio-economic factors explains the

46 decline in forest cover in North Korea, particularly during the 1980s and the 1990s when the

47 decline was sharp (Lee et al. 1999).

49 One of the most important factors is thought to be conversion of forest to farmland. Food

50 shortage was already a problem in North Korea in the 1980s, largely due to declining agricultural

51 productivity (Kim 2005) and stagnating economy (Park et al. 2009). One of the measures to

52 alleviate food shortage was to expand farmland, particularly in hilly areas as terraced fields. This

53 type of farmland is called a darakbat in Korean. Even though darakbats were built as part of a

54 government program to expand productive farmlands, many of them were poorly built and 55 managed, and resulted in land degradation and low productivity (Lee et al. 2005). Logging can

56 be pointed out as another major contributor to deforestation. Energy was already in short supply

57 in the 1980s, too (Kim 2005). Lack of energy supply reduced agricultural productivity and 58 deepened economic hardship. People adapted to energy shortage by logging in the absence of 
government monitoring (Park et al. 2009).

61 Deforestation not only reduces biomass stock and ecological integrity, but also exacerbates flood

62 damage (Bradshaw et al. 2007). Big floods are not uncommon in North Korea, but those in 1995

63 and 1996 were particularly devastating (Kim and Ryu 2009). The floods in July and August of

641995 resulted in displacement of 5.4 million people, destruction of 330,000 hectares of

65 agricultural land, and loss of 1.9 million tons of grains (Noland et al. 2001). The 1996 floods

66 were less severe but occurred well before recovery from the previous year's floods. Such floods

67 were caused by downpours with decades-long cycles but the damage was exacerbated due to 68 environmental degradation (Kim 1999).

70 In general, not a lot of studies are found regarding deforestation in North Korea. Some studies

71 examined deforestation in North Korea in terms of overall statistics (Lee et al. 1999) or for a

72 limited area (Tang et al. 2010). However, morphological studies on land cover change are hard to

73 find. A noticeable example of morphological studies was conducted by Zheng et al. (1997). They

74 examined forest changes in the Changbai (Baekdu in Korean) Mountain Reserve located on the

75 China-North Korea border between 1972 and 1988 to find that forest became more fragmented

76 and smaller in size. Not only reduction but also fragmentation of forest cover can be a threat to

77 ecological integrity and sustainability. The forest ecosystem in North Korea is inhabited by

78 various animals, plants (mostly trees) and microorganisms (Piddington 2003), and it has been

79 well documented that the forest ecosystem continues to decrease in size. However, it is rarely 
80 documented how the forest is changing in shape. Negative effects of habitat fragmentation have

81 been widely studied (Fahrig 2003), and we certainly think that it is happening in North Korea's

82 forest. The definition of habitat fragmentation is diverse, but the diverse definitions imply four

83 main effects on habitat pattern (Fahrig 2003 p. 491): (1) reduction in habitat size, (2) increase in

84 number of habitat patches, (3) decrease in sizes of habitat patches, (4) increase in isolated

85 patches. These four elements form a guideline on how to examine morphological changes in

86 forest in North Korea.

88 The purpose of the study was to quantitatively analyze morphological changes in forest cover in

89 North Korea between the 1980s and 2000s. The novelty of the study is that this is the first

90 attempt, to the best of our knowledge, to analyze morphological changes in forest for the entire

91 North Korea. During the time, North Korea had the first ever leadership change (or hereditary

92 succession) and underwent socio-economic changes. The results from the study are expected to

93 provide a basis for scientific research on social and ecological effects of forest fragmentation.

94 The Materials and Methods section introduces data used and our analysis methods,

95 Morphological Spatial Pattern Analysis (MSPA) and network analysis. Following the guideline

96 suggested by Fahrig (2003), our analysis focused on the size, frequency, and connectivity of

97 forest patches. We hypothesized that during the time period in North Korea forest patches

98 generally decreased in size, increased in frequency, and isolated patches or strips of forest

99 increased in frequency. The Results and Discussion section presents statistics and maps from the 100 analyses, and is followed by conclusion and recommendations. 


\section{Materials and Methods}

104 Land cover data

106 Land cover data as images were obtained for the years 1980, 1990, and 2000 from the Web site

107 of the Republic of Korea's (South Korea) Ministry of Environment 108 (http://egis.me.go.kr/bc/largeGrdCover_2000.do). Each data set was produced from the Landsat 109 TM imagery taken for three years for the entire Korean Peninsula. The spatial resolution of the 110 Landsat imagery is $30 \mathrm{~m}$, but the land cover data maps were available at a $100-\mathrm{m}$ spatial 111 resolution. They had more than $70 \%$ accuracy for classification in the North Korean region. It 112 should be noted that ground truthing is virtually impossible in North Korea due to political 113 reasons. Land cover types had already been classified into urban, agricultural, grassland, forest, 114 wetland, barren, and open water using the unsupervised classification method.

116 First, the portion of North Korea was clipped out from the original data sets for the three years.

117 The land cover maps were then pre-processed to produce the binary foreground and background 118 image files, where foreground is the land cover of interest and background is the rest. Here forest 119 pixels constitute foreground ( 2 bytes) and non-forest ones background ( 1 byte) in the 
120 terminology of MSPA used in the study. Next, the pre-processed image files were converted to

121 8-bit TIFF files without compression in a geographic information system (GIS) environment.

122 After the series of processes, the image files for the years 1980, 1990, and 2000 were made ready

123 for the morphological analysis.

125 Fig. 1 shows the land cover in North Korea for 2000. The land cover is overlaid by provincial 126 boundaries. Generally the eastern half of the country is heavily forested and the western half is 127 more dominated by agricultural land. Pyongyang is the largest metropolitan area and is a special 128 administrative district as the capital of the country.

132 Morphological changes of forest cover were analyzed using the Morphological Spatial Pattern 133 Analysis (MSPA) (Soille and Vogt 2009). MSPA is based on concepts from mathematical 134 morphology (Soille 2003), and segments arbitrary binary patterns into a series of categories or 135 classes representing different size, shape, and connectivity (Soille and Vogt 2009). In other 136 words, when there is a binary raster data set (forest or foreground $=1$, non-forest or background $137=0$ ), MSPA analyzes the patterns of forest (foreground) cells and categorize based on the size, 138 shape, and connectivity of the cells. This is a useful alternative to overlaying multiple thematic 139 layers in a GIS environment for mapping green infrastructure such as forest, because it only 140 requires a single, binary layer (Wickham et al. 2010). 
142 A size-parameter, $s$, is used as a threshold to determine the categories, and defined as $\sqrt{u^{2}-b^{2}}$

143 where $a$ and $b$ are the distance along the horizontal and vertical axes, respectively, between any

144 two pixels (Soille and Vogt 2009). Connectivity between pixels is defined based on one of two

145 rules, eight-neighbors and four-neighbors. If $s=1, a=0$ and $b=1$ (or vice versa), it corresponds

146 to the width of one pixel. If an eight-neighbor rule is chosen for foreground, a four-neighbor rule

147 is applied for background, or vice versa.

149 MSPA has seven mutually exclusive morphological categories: core, islet, loop, bridge, 150 perforation, edge, and branch (Soille and Vogt 2009). The definition of the categories is given in

151 Table 1 according to Soille and Vogt (2009) and illustrated in Fig. 2. Core and islet pixels can be 152 viewed as patches of foreground pixels, while islet pixels are not connected to any other

153 category. Branch pixels extend out from an area of core but do not connect to another area of 154 core. Core can be viewed as hub, and bridge is equivalent to corridor or link in the literature of 155 ecological networks (Wickham et al. 2010). The selection of the size-parameter $s$ affects the 156 minimum size of core and the number of core pixels, and the relationship is non-linear 157 (Wickham et al. 2010).

159 Table 1 Definition of morphological categories.

\begin{tabular}{|l|l|l|}
\hline Type & Category & Definition \\
\hline Patch & Core & Foreground pixels whose distance to the background is \\
\cline { 2 - 3 }
\end{tabular}




\begin{tabular}{|l|l|l|}
\hline \multirow{3}{*}{ Connector } & Bridge & greater than $s$ \\
\cline { 2 - 3 } & Islet & $\begin{array}{l}\text { Patch of foreground pixels that do not contain any core } \\
\text { pixel }\end{array}$ \\
\cline { 2 - 3 } Boop & $\begin{array}{l}\text { Pixels emanating from two or more core connected } \\
\text { components }\end{array}$ \\
\hline & Perforation & $\begin{array}{l}\text { Pixels emanating from the same core connected } \\
\text { component }\end{array}$ \\
\cline { 2 - 3 } & Edge & $\begin{array}{l}\text { Pixels whose distance to the core pixels is lower than or } \\
\text { equal to } s \text { and located within a core } \rightarrow \text { inner boundary }\end{array}$ \\
\hline & $\begin{array}{l}\text { Pixels whose distance to the core pixels is lower than or } \\
\text { equal to } s \text { and facing background on other sides } \rightarrow \text { outer } \\
\text { boundary }\end{array}$ \\
\hline
\end{tabular}

161 To perform MSPA, we used the GUIDOS (Graphical User Interface for the Description of image

162 Objects and their Shapes) program available online for free from European Commission Joint

163 Research Centre (http://forest.jrc.ec.europa.eu/download/soft-ware/guidos). We used eight-

164 neighbor connectivity for foreground and the size-parameter value of one. Since the spatial

165 resolution of the data used here is $100 \mathrm{~m}$, we set the edge width at $100 \mathrm{~m}$.

\section{Network analysis}

169 A network analysis was conducted on the MSPA results by employing GUIDOS. The analysis is

170 based on the graph-theory application (Saura and Torne 2009). A graph in the analysis is a

171 collection of vertices or nodes and edges or links that connect nodes. In the terminology of

172 GUIDOS's network analysis, nodes are cores and links are bridges, and the remaining MSPA

173 classes including islet, loop, perforation, edge, and branch, are neglected (Vogt 2010). Bridges 
174 are connectors between different cores. A connected set of nodes and links is called a component

175 - as an interchangeable term of the graph — in GUIDOS. Thus, a set of cores without any links 176 (i.e. nodes only) will not be considered as a component in this study.

\section{$178 \quad$ Results and Discussion}

180 We present the results in the following subsections: land cover change, forest cover change, 181 morphological changes of forest, and forest network change. The land cover change subsection 182 presents overall statistics of all land cover types during the three decades. The forest cover 183 change subsection presents detailed information regarding the amount of forest cover. The 184 morphological changes of forest subsection presents the results from the MSPA, and the forest 185 network change subsection presents those from the network analysis.

\section{Land cover change}

189 Table 2 shows the fraction of each land cover type for the years $1980-2000$ to the entire area of 190 North Korea. Between 1980 and 1990, forest decreased by 4 percentage points whereas 191 agricultural fields increased by 2 percentage points. Between 1990 and 2000, forest decreased by 19213 percentage points whereas grassland increased by 7 percentage points and agricultural fields 193 by 4 percentage points. Urban lands increased by up to 1 percentage point for each decade. It 
194 seems forest was replaced largely with agricultural and grassland. Grassland increased a lot 195 between 1990 and 2000, and is generally located between agriculture and forest (see Fig. 1). We

196 speculate that it indicates degradation of forest cover. Urban lands increased about $50 \%$ each 197 decade, but are still quite small in size.

198

199 Table 2 Fraction of land cover types to the entire land area of North Korea

\begin{tabular}{|l|r|r|r|}
\hline Lear & \multicolumn{1}{|r|}{1980} & \multicolumn{1}{l|}{1990} & 2000 \\
\hline Open water & & & \\
\hline Urban & $2.0 \%$ & $2.1 \%$ & $1.4 \%$ \\
\hline Barren land & $1.1 \%$ & $1.6 \%$ & $2.6 \%$ \\
\hline Wetland & $0.8 \%$ & $1.4 \%$ & $0.4 \%$ \\
\hline Grassland & $0.4 \%$ & $0.4 \%$ & $3.0 \%$ \\
\hline Forest & $4.0 \%$ & $4.8 \%$ & $11.6 \%$ \\
\hline Agricultural & $74.6 \%$ & $70.5 \%$ & $57.7 \%$ \\
\hline TOTAL & $16.9 \%$ & $19.0 \%$ & $23.2 \%$ \\
\hline
\end{tabular}

200

201

\section{Forest cover change}

203 
204 Table 3 portrays overall changes in forest in North Korea between 1980 and 2000, and suggests 205 that deforestation accelerated during the 1990s. From 1980 to 1990 it decreased by 5\% and from

2061990 and 2000 it decreased by $18 \%$. It is generally known that the sharp deforestation in the $2071990 \mathrm{~s}$ is related to severe famine that led to the so-called 'Arduous March' 208 (http://tinyurl.com/2e7eefu). During the same time, both urban and agricultural lands increased 209 (see Table 2).

211 Table 3 Changes in forest cover in North Korea

\begin{tabular}{|l|l|l|l|l|}
\hline Year & $\begin{array}{l}\text { Total area } \\
\left(\mathrm{km}^{2}\right)\end{array}$ & $\begin{array}{l}\text { Forest area } \\
\left(\mathrm{km}^{2}\right)\end{array}$ & $\begin{array}{l}\text { Change from previous } \\
\text { data }\left(\mathrm{km}^{2}\right)\end{array}$ & $\begin{array}{l}\text { Percent change } \\
\text { from previous } \\
\text { data }\end{array}$ \\
\hline 1980 & 122,762 & 91,717 & N/A & N/A \\
\hline 1990 & 122,762 & 86,678 & $-5,039$ & $-5 \%$ \\
\hline 2000 & 122,762 & 70,858 & $-15,820$ & $-18 \%$ \\
\hline
\end{tabular}

213 Fig. 3 shows fraction of forest cover in each province between 1980 and 2000. Between 1980

214 and 1990, forest cover fraction decreased particularly in Yanggang-do, Hamgyeongbuk-do,

215 Raseon-si, and Nampo-si. The first three are in the northeast and Nampo-si is on the west coast,

216 close to Pyongyang-si. Tang et al. (2010) report that the forest in the Baekdu area, located in

217 Yanggang-do on the border with China, continued to degrade largely due to strip logging by the 218 early 2000s. Between 1990 and 2000, forest cover decreased particularly in Jagang-do, 219 Gaeseong-si, Gangweon-do, Pyeonganbuk-do, Pyeongannam-do, Hwanghaenam-do, 220 Pyongyang-si, and Nampo-si. Except for Gangweon-do, all are located in the western half of the 221 country, which is different from the period 1980-1990. They include three urban provinces 
222 (Gaeseong, Pyongyang and Nampo), and Pyeongannam-do and Hwanghaenam-do border at least

223 two of the urban provinces respectively.

227 MSPA categories of forest in North Korea are shown in Fig. 4 for the three different years. What

228 is noticeable between 1980 and 1990 includes a large increase in islet class in south of

229 Pyongyang, clearing of forest in the northwestern corner of the country, and widespread 230 conversion from core to bridge classes in the northeastern 'arm'. Deforestation is obvious, but

231 fragmentation was of problem as much. There is a large harbor city south of Pyongyang, called 232 Nampo, along the long narrow inlet. The northwest corner of the country has been a long-time 233 gateway to China and an industrial center since the early $20^{\text {th }}$ century. At the same time, 234 topography-wise, the western part of North Korea is where most of plains are located, thus a lot 235 of agricultural fields. Considering that urban areas occupy a very small fraction of the land area, 236 conversion to farmland is thought to have had more influence than urban and industrial 237 development. Urban areas increased by less than 2 percentage points during 1980-2000 238 nationwide, whereas farmland increased by 6 percentage points (Table 2). On the other hand, the 239 northeastern 'arm' has very high (easily exceeding $2000 \mathrm{~m}$ above sea level) mountains and 240 plateaus, and is the most remote part of the country. Therefore fragmentation in the area may be 241 due largely to individual and local activities. 
243 Between 1990 and 2000, a large decrease in core, bridge, and islet classes in the southwest is

244 remarkable. Not just core shrank in size but also a lot of bridge and islet disappeared. It coincides

245 with a large increase in agricultural land during the period. The land cover maps showed that

246 agricultural lands substantially increased during the time in the western part of the country.

247 Many of small cores in the southwest are surrounded by agricultural lands.

249 The upper panel of Fig. 5 portrays the fraction of MSPA classes to the entire country, and the 250 lower panel portrays the changes in the fraction of the MSPA classes out of the entire forest 251 cover. Therefore the upper panel shows absolute changes (smaller fractions meaning smaller in 252 area) whereas the lower panel shows relative changes within forest. In the upper panel core 253 continues to decrease whereas in the lower panel it decreased and increased during the time. 254 Because the graphs show fractional changes, a smaller fraction of core does not necessarily mean 255 fewer cores. The fraction of core to the entire land area decreased along with overall 256 deforestation during the time, but its areal share within forest increased between 1990 and 2000.

257 Both graphs show that bridge increased and then decreased. Because bridges connect cores, if 258 cores become smaller, some core cells convert to bridge cells. The opposite trends between core 259 and bridge in the lower panel can be explained in this way. Both core and bridge decreased 260 absolutely during 1990-2000 (upper panel), but core increased relatively and bridge decreased 261 (lower panel). The relative decline of bridge seems to be related to the increase in branch 262 because bridge becomes branch when the connection to core is broken. Islet and edge continued 263 to increase both absolutely and relatively. Increasing fractions of islet and edge suggest an 264 increasing degree of fragmentation. Islet is unconnected to anything and too small to be core, and 
265 edge increases when cores are broken or change shape.

267 Fig. 6 portrays the frequency of MSPA classes occurring as individual objects. Core, islet, edge,

268 bridge and branch increased in number between 1980 and 2000 . With core area continuing to

269 decrease absolutely, the increasing number of core in the figure suggests smaller cores, a sign of

270 defragmentation. Islet, edge, and branch both increased in size and number, strongly suggesting

271 defragmentation. Bridge is somewhat unique. Its frequency increased along with core. With

272 more and smaller cores, it makes sense that bridge increased in number. However, the total area

273 of bridge decreased both absolutely and relatively between 1990 and 2000 when the frequency

274 increased remarkably. We think this is another sign of fragmentation. With more and smaller 275 cores, bridges increased in number, and at the same time, individual bridges became much

276 shorter, connecting fragmented cores, or were converted to non-forest.

278 Forest network change

280 Fig. 7 portrays the changes in forest network between 1980 and 2000. In the figures, each color 281 other than light grey represents a component. In 1980, there was a very large (blue) component 282 covering most of the country, and several small ones mostly in the southwest. In 1990, the large 283 blue component became more porous, revealing more light grey pixels in it, and shrank in 284 overall size. The contraction of the blue component is very startling in 2000 . It is most visible in 285 the central and southern parts of the country. At the same time, the North Korean-Chinese border 
286 region experienced substantial fragmentation. Unlike in 1980 or 1990, the border is covered with

287 pixels other than blue, meaning small networks separated from the large blue component.

289 Wickham et al. (2010) said that identifying and mapping of ecological networks are a significant

290 part of green infrastructure research, and focused on forest and wetland for their green

291 infrastructure mapping in the United States. In North Korea, the concept of green infrastructure

292 is premature considering its dire economic and political conditions, but it is not too early to

293 conduct research about its green infrastructure, particularly forest, before it degrades irreparably.

294 North Korea shares borders with South Korea and China, and forest crosses the borders. Human

295 activity degrading forest is constrained by the border, but the negative consequences, such as

296 increased sediment loads in streams or riverine flooding are not. The present study identified

297 degradation of forest cover in North Korea both in terms of quantity and quality, which can be of

298 interest both to environmental managers in South Korea and China.

300 Conclusion and Recommendations

302 We examined the changes in forest cover in North Korea between the 1980s and 2000s using the 303 Morphological Spatial Pattern Analysis (MSPA) and network analysis. The findings are 304 summarized as follows: (1) Forest cover sharply decreased between the 1990s and 2000s, 305 particularly in western provinces; (2) Morphological classes indicating fragmentation such as 
306 islet, branch and edge consistently increased in their fraction to the total area between the 1980s

307 and 2000s; (3) Islet, branch and edge also increased in frequency during the same period; (4)

308 Forest networks shrank in size and increased in number. Overall, the results demonstrate that

309 deforestation and fragmentation of forest occurred simultaneously in North Korea during the

310 time.

312 These morphological changes might have been considerably influenced by various land use

313 practices including urbanization, agricultural land expansion, industrial development, or other

314 activities. However, it is difficult not only to pinpoint the main causes of these changes but also

315 to interpret how they interact with each other. Better understanding of cause and consequence

316 relations regarding our findings is deferred to the next step in research.

318 Our study emphasized the importance of analyzing forest degradation in the form of 319 fragmentation. North Korea's forest stock not only decreased in amount but also degraded 320 resulting in poorer connectivity. Restoring forest in North Korea may require an enormous 321 amount of resources, therefore it is important to set priority. To maximize benefit with limited 322 resources, we think restoration efforts should focus on improving connectivity of forest, which 323 currently receives a lot of attention in ecology and land conservation planning (Saura and Torne 324 2009). Therefore, it is important to understand the morphological pattern of forest, and it can be 325 done using the approaches of our study. Future studies in this topic need to extend beyond the 326 borders with South Korea and China. 
$328 \quad$ Figure Captions

329

330 Fig. 1 Land cover and provincial boundaries of North Korea in year 2000, with the inset map

331 showing neighboring South Korea and China and major cities

332 Fig. 2 Illustration of morphological categories in MSPA (Image captured from the study results)

333 Fig. 3 Fraction of forest cover to the entire land area by province, 1980-2000

334 Fig. 4 Map of MSPA classes for 1980 (a), 1990 (b), and 2000 (c) and their fractions to the entire

335 land area. The fractions may not add up to $100 \%$ due to rounding.

336 Fig. 5 Fraction of MSPA classes to the entire country (upper panel) and to the entire forest

337 (lower panel), 1980-2000. The information in the upper panel also appears in the Fig. 4 legend.

338 Fig. 6 Frequency of each MSPA class occurring as individual objects, 1980-2000

339 Fig. 7 Map of forest network for 1980 (a), 1990 (b), and 2000 (c). Each color other than grey

340 represents a network component. 


\section{References}

345 Bradshaw CJA, Sodhi NS, Peh K, Brook BW (2007) Global evidence that deforestation

346 amplifies flood risk and severity in the developing world. Global Change Biol 13:2379-2395.

347 doi: 10.1111/j.1365-2486.2007.01446.x

348 Fahrig L (2003) Effects of Habitat Fragmentation on Biodiversity. Annual Review of Ecology,

349 Evolution, and Systematics 34:487-515

350 Kim C (1999) Lack of recovery from flood damage and its cause in North Korea analyzed via

351 remote sensing imagery. Magazine of Korea Water Resources Assoc 32:53-57

352 Kim J, Ryu M (2009) Analysis of weather forecast and relevant technologies to deal with natural

353 disaster in North Korea. North Korean Studies Review 13:97-122

354 Kim YH (2005) A study on ecological restoration measures for the degraded land in North

355 Korea: Focusing on South Korea's restoration policy. North Korean Studies Review 9:21-48

356 Korea Institute for National Unification (2009) 2009 Bukhangaeyo. Korea Institute for National

357 Unification, Seoul

358 Lee K, Joung M, Yoon J (1999) Content and characteristics of forest cover changes in North

359 Korea. J Korean Forestry Society 88:352-363

360 Lee M, Kim N, Lee G, Han U (2005) A study on the surface erosion by the development of

361 cropland on the hillslope in the west coast area of North Korea using Quick Bird satellite images.

362 J Korean Assoc of Regional Geographers 11:453-462Noland M, Robinson S, Wang T (2001) 
363 Famine in North Korea: Causes and cures. Economic Development and Cultural Change 49:741$364 \quad 767$

365 Park K, Lee S, Park S (2009) A study on the North Korea's change of forest policy

366 since the economic crisis in 1990's. Korean J Unification Affairs 51:459-492

367 Piddington K (2003) DPR Korea: State of the Environment 2003. United Nations Environment

368 Programme

369 Saura S, Torne J (2009) Conefor Sensinode 2.2: A software package for quantifying the

370 importance of habitat patches for landscape connectivity. Environmental Modelling \& Software

371 24. doi: 10.1016/j.envsoft.2008.05.005

372 Soille P, Vogt P (2009) Morphological segmentation of binary patterns. Pattern Recog Lett 30.

373 doi: 10.1016/j.patrec.2008.10.015

374 Soille P (2003) Morphological Image Analysis: Principles and Applications. Springer-Verlag, 375 New York

376 Tang L, Shao G, Piao Z, Dai L, Jenkins MA, Wang S, Wu G, Wu J, Zhao J (2010) Forest

377 degradation deepens around and within protected areas in East Asia. Biol Conserv 143:1295-

378 1298. doi: 10.1016/j.biocon.2010.01.024

379 Vogt P (2010) User Guide of GUIDOS 1.3:17. Institute for Environment and Sustainability,

380 Ispra

381 Wickham JD, Riitters KH, Wade TG, Vogt P (2010) A national assessment of green

382 infrastructure and change for the conterminous United States using morphological image 
383 processing. Landscape Urban Plann 94. doi: 10.1016/j.landurbplan.2009.10.003

384 Zheng D, Wallin D, Hao Z (1997) Rates and patterns of landscape change between 1972 and 3851988 in the Changbai Mountain area of China and North Korea. Landscape Ecol 12:241-254.

386 doi: $10.1023 / \mathrm{A}: 1007963324520$

387 